\title{
Os Parques Estaduais do Tocantins: ameaças e atividades críticas no gerenciamento
}

O processo de criação de áreas protegidas no mundo como estratégia para preservar de forma permanente grandes áreas de uso restrito pelo ser humano é antigo sendo que o Brasil seguiu a tendência mundial quanto ao conceito de Unidades de Conservação (UCS). Foi a partir da Lei no 9.985 de julho de 2000 que entrou em vigência o Sistema Nacional de Unidades de Conservação da Natureza (SNUC) que regulamenta o funcionamento das atuais UCs brasileiras. Neste contexto o estado do Tocantins teve seus Parques Estaduais criados sob influência desse novo modelo de áreas protegidas, e ao mesmo tempo em que existem leis específicas para o planejamento e administração das UCs, existem ferramentas de avaliação para a gestão destas áreas, permitindo acompanhar o desenvolvimento e faze avaliação dos seus procedimentos administrativos. Diante do cenário político atual no Brasil é importante avaliar os resultados de ferramentas já testadas e validadas. Assim, a pesquisa teve como objetivo analisar os fatores que influenciaram na gestão, as ameaças e as atividades críticas ao gerenciamento dos Parques Estaduais do Cantão (PEC), Jalapão (PEJ) e Lajeado (PEL) no período de 2009 a 2018, através das informações constantes na Ferramenta Management Effectiveness Tracking Tool (METT). Os resultados permitiram identificar as principais ameaças e atividades críticas para o gerenciamento destas UCs, sendo o PEC o melhor avaliado na média geral com o conceito Bom, seguido pelo PEJ e PEL respectivamente, que obtiveram o conceito Regular. As ameaças como caça, pesca, visitação desordenada, falta de regularização fundiária, queimadas e as atividades críticas como baixa quantidade de guarda-parques para monitorar as atividades, juntamente com o número mínimo de profissionais de nível superior em áreas específicas e a rotatividade de profissionais, fizeram se presentes no cotidiano das UCs, afetando seu pleno desenvolvimento em função da não resolução dos problemas indicados pelos gestores.

Palavras-chave: Parques Estaduais; Gestão Ambiental; Ameaças; Tracking Tool.

\section{Tocantins State Parks: threats and critical activities in management}

Following the long established global effort to create protected areas, Brazil has embraced the concept of Conservation Units (UCs) as a strategy to permanently preserve large areas of restricted use by humans. The National System of Conservation Units (SNUC) came into force through the Law No. 9,985, of July 2000, which regulates the operation of current Brazilian UCs. In this context, the state of Tocantins had its State Parks created under the influence of this new model of protected areas. While there are specific laws for planning and administration of UCs, there are assessment tools to manage them, by monitoring and assessing administrative procedures. Given the current political scenario in Brazil, it is important to evaluate the results of tools that have already been tested and validated. Thus, this research aimed to analyze the factors that influenced operations, threats and activities critical to the management of the Cantão State Park (PEC), Jalapão State Park (PEJ) and Lajeado State Park (PEL), from 2009 to 2018, through data collected in the Management Effectiveness Tracking Tool (METT). The results made it possible to identify the main threats and critical activities for the management of these UCs, with PEC being the best rated in the general average with the Good concept, followed by PEJ and PEL respectively, which obtained the Regular concept. There were observed threats such as hunting, fishing, irregular visitation, lack of land regularization and fires. On top of that, critical activities such as low number of park rangers to monitor activities, together with the minimum number of higher education professionals in specific areas and labor turnover, were part of the daily life of the UCs, affecting their full operation due to the non-resolution of the issues pointed out by the managers.

Keywords: State Parks; Environmental Management; Threats; Tracking Tool.

Topic: Planejamento, Gestão e Políticas Públicas Ambientais

Reviewed anonymously in the process of blind peer.

Alessandro Lemos de Oliveira (iD

Instituto Federal do Tocantins, Brasil

http://lattes.cnpq.br/9956827080283023

http://orcid.org/0000-0002-2709-5076

alessandro.oliveira@ifto.edu.br

Elineide Eugênio Marques (ib)

Universidade Federal do Tocantins, Brasil

http://lattes.cnpq.br/9875056556045599

http://orcid.org/0000-0003-0223-6853

emarques@mail.uft.edu.br

Sandro Sidnei Vargas de Cristo

Universidade Federal do Tocantins, Brasil

http://lattes.cnpq.br/6004596653256447

http://orcid.org/0000-0003-4054-5761

sidneicristo@mail.uft.edu.br
Received: $\mathbf{1 7 / 0 3 / 2 0 2 0}$

Approved: 22/04/2020

\section{Referencing this:}

OLIVEIRA, A. L.; MARQUES, E. E.; CRISTO, S. S. V.. Os Parques Estaduais do Tocantins: ameaças e atividades críticas no gerenciamento. Revista Ibero Americana de Ciências Ambientais, v.11, n.3, p.411-425, 2020. DOI: http://doi.org/10.6008/CBPC2179-6858.2020.003.0032 


\section{INTRODUÇÃO}

Embora a estratégia de proteção e conservação de áreas de interesse comum pelo ser humano seja antiga, percebe-se que o crescimento da população mundial e a exploração dos recursos naturais, sem o devido cuidado, têm contribuído com o incremento dos impactos ambientais, tornando necessário que sejam criados meios para a manutenção e conservação de diversos tipos de ambientes naturais. Segundo Santos (2014), uma das mais antigas referências documentadas vem da Ásia, onde o Imperador Ashoka, da Índia, em 252 a.C., ordenou a proteção de certos animais, peixes e áreas florestadas.

Em se tratando de período recente, surge no século XIX a utilização do conceito de Unidade de Conservação (UC), como estratégia para preservar de forma permanente grandes áreas intocadas pelo homem, ocorrendo, no ano de 1872, a criação do Parque Nacional de Yellowstone, nos Estados Unidos. Ainda que iniciativas semelhantes tenham surgido em outros lugares do mundo, como por exemplo, as reservas de caça da realeza europeia, foi da evolução do conceito de Parque Nacional, na forma instituída em Yellowstone, que surgiram os sistemas de UCs reproduzidos mundialmente (MORSELLO, 2001).

Em relação ao Brasil, os registros históricos indicam que tanto a coroa portuguesa quanto o governo Imperial já haviam empreendido algumas iniciativas destinadas à proteção, à gestão ou ao controle de determinados recursos naturais (MEDEIROS, 2006). Entretanto para se chegar ao atual conceito e estruturação de UC e a destinação de áreas protegidas no Brasil, assim como o desenvolvimento de sua política conservacionista, existiram muitas influências do cenário internacional (AMBRÓSIO, 2014).

Autores, como Diegues (2001) e Ferreira (2004), descrevem o Parque Nacional (PN) do Itatiaia no Rio de Janeiro, criado em 1937, como a primeira área protegida do Brasil, já com base no Código Florestal de 1934. Há relatos de que, em 1916, por influência de Santos Dumont, foi criado o Parque Nacional do Iguaçu, localizado no Paraná, que só foi federalizado em 1939 (VALE, 2012). Desde então, várias UCs foram criadas em vários estados brasileiros pelos governos Federal, Estaduais e Municipais.

A criação do Sistema Nacional de Unidades de Conservação da Natureza (SNUC), no ano de 2000 definiu critérios objetivos para a concepção e gestão de algumas tipologias e categorias de áreas protegidas, que antes se encontravam dispersas em diferentes instrumentos legais, sendo uma modificação importante na estrutura de grande parte das áreas protegidas brasileiras (MEDEIROS, 2006). Por meio da Lei no 9.985 de julho de 2000, as UCs passam a ser organizadas em dois grupos com características específicas, sendo estas as Unidades de Proteção Integral (UPI) e as Unidades de Uso Sustentável (UUS), totalizando 12 categorias (BRASIL, 2000).

Ressalta-se que o estado do Tocantins é novo, sendo cunhado a partir da promulgação da Constituição Federal de 05 de outubro de 1988 e implantado em 10 de janeiro de 1989. Desta forma, as UPIs que foram implementadas entre os anos de 1998 e 2001, diferente de UCs existentes em outros estados no Brasil, foram criadas em um contexto de influência de pré-criação do SNUC, como é o caso do Parque Estadual do Cantão (PEC), ou logo após o período recente de sua criação, no caso do Parque Estadual do Jalapão (PEJ) e do Parque Estadual do Lajeado (PEL). Por outro lado, a normatização sobre como deveriam ser criadas, 
gerenciadas e avaliadas foi oficializada pelo governo do Tocantins em 2005, com a instituição de seu sistema Estadual de Unidades de Conservação (SEUC), por meio da Lei no. 1.560, de 05 de abril de 2005 (TOCANTINS, 2005).

Deste modo, o Brasil contribuiu diretamente com cerca de $75 \%$ das áreas protegidas criadas no mundo desde 2003, de acordo com dados da UICN et al. (2011). Entretanto para que o cumprimento da Convenção sobre Diversidade Biológica (CDB) alcance melhores resultados, deve envolver, também, a avaliação da efetividade de gestão das mesmas, com uso de ferramentas de monitoramento do alcance dos resultados, metas e ameaças, conforme previstos no acordo da CDB, e nesse processo deve-se considerar os aspectos técnicos, políticos e econômicos, condição que pode ser considerada essencial ao cumprimento dos objetivos de criação das UCs (HOCKINGS et al., 2006).

Entre as ferramentas disponíveis para o auxílio dos gestores na avaliação e identificação de ameaças e atividades críticas no gerenciamento dessas áreas, está a Ferramenta Management Effectiveness Tracking Tool (METT) ou Ferramenta de Avaliação Rápida de Efetividade de Gestão em Áreas Protegidas, que foi desenvolvida pelo Banco Mundial em conjunto com a Rede World Wildlife Fund (WWF), com o objetivo de monitorar o avanço na eficácia de gestão das áreas apoiadas pelo Banco, por meio de programas e projetos de implementação e fortalecimento. O Tracking Tool busca relatar avanços nas UCs, possibilitando monitorar o progresso temporal das mesmas e já foi aplicada em mais de 200 áreas protegidas, em 34 países (HIGGINSZOGIB et al., 2006).

Desde o ano de 2009, o Tracking Tool já é utilizado como instrumento de avaliação de UCs no estado do Tocantins. A partir de setembro de 2013, a Secretaria de Estado de Meio Ambiente e Recursos Hídricos do Tocantins (SEMARH) incorporou o Tracking Tool ao Sistema Informatizado de Gestão das Unidades de Conservação do Tocantins (GESTO), permitindo o acompanhamento dos resultados das avaliações realizadas pelos gestores (SEMARH, 2014).

Estudos recentes realizados por Hockings et al. (2006) demonstram que a avaliação da efetividade de áreas protegidas provê dados que podem orientar os gestores nas tomadas de decisões, como alocação de recursos humanos e financeiros, priorização de procedimentos de monitoramento, pesquisa e proteção, facilitando a identificação de lacunas técnicas, com potencial de ser um meio de negociação de apoio financeiro, técnico e político, incentivando também a cooperação entre equipes e troca de informações entre os gestores.

As ações governamentais em níveis federal, estadual e municipal podem gerar resultados positivos ou negativos para gestão das UCs. Como exemplos de ações governamentais, ainda a serem resolvidas, podem ser citados: problemas fundiários em áreas protegidas, a deficiência ou ausência de infraestrutura básica e de funcionários atuantes na elaboração das políticas e estratégias, assim como na fiscalização dos regramentos, ausência ou falta de atualização de planos de manejo, e destinação de recursos insuficientes para implantação e manutenção. Esta situação gera problemas maiores, dificultando a implementação efetiva das UCs no Brasil (MEDEIROS et al., 2011).

As dificuldades inerentes à implementação de áreas protegidas no Brasil disseminaram a expressão 
"parques de papel" para se referir à institucionalização das UCs através de instrumento legal, mas que não garante, de fato, a efetividade dos objetivos para a qual foi criada (DIAS, 2018).

Assim, o estudo dos resultados de avaliações padronizadas realizadas em áreas protegidas no estado do Tocantins, que foram criadas no contexto de uma nova base conceitual em relação ao modo como essas áreas deveriam ser implantadas e gerenciadas, por meio das discussões e implantação do SNUC, possibilitam verificar os resultados obtidos e como estes estão sendo tratados pelo órgão competente, a fim de solucionar as demandas pendentes para o cumprimento das funções para as quais foram criadas.

Face ao exposto, o objetivo desta pesquisa é analisar os fatores que influenciaram na gestão, as ameaças e as atividades críticas ao gerenciamento dos Parques Estaduais do Cantão (PEC), Jalapão (PEJ) e Lajeado (PEL), por meio das informações que constam na Ferramenta Management Effectiveness Tracking Tool (METT), entre os anos de 2009 e 2018.

\section{MATERIAIS E MÉTODOS}

\section{Caracterização da Área de Estudo}

A pesquisa envolve os Parques Estaduais do Cantão, Jalapão e Lajeado (Figura 1), que são Unidades de Proteção Integral, localizadas no Estado do Tocantins, criadas entre os anos de 1998 e 2001.

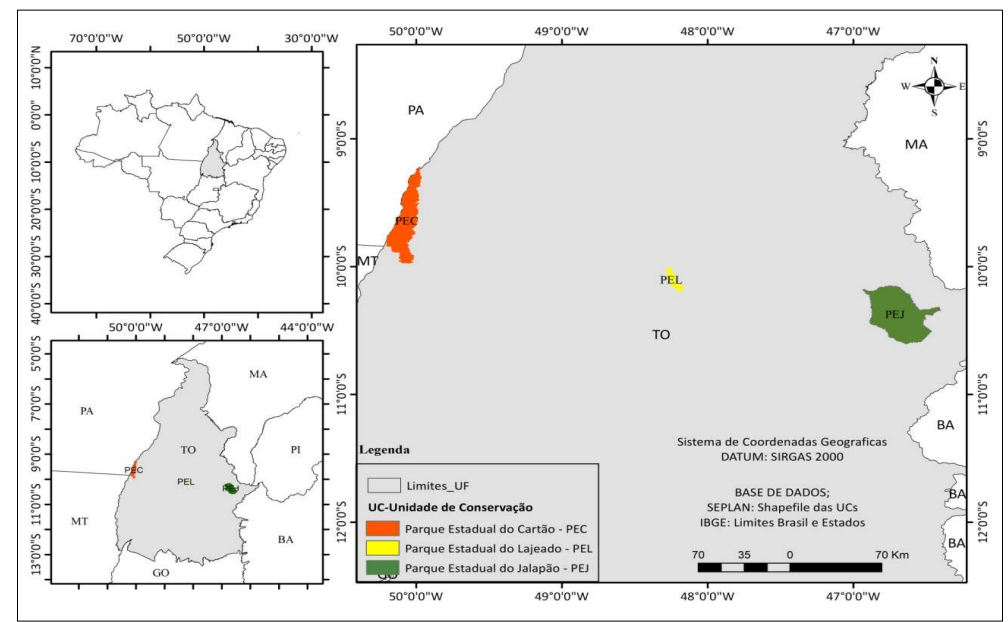

Figura 1: Localização das áreas de estudo no Estado do Tocantins, Brasil.

As unidades selecionadas apresentam características particulares quanto à criação, comunidades afetadas e motivos pelos quais foram criadas. O Quadro 1 apresenta uma síntese de informações selecionadas que contextualizam as UCs estudadas.

O PEC foi a primeira Unidade de Conservação de Proteção Integral criada no Estado do Tocantins, no ano de 1998, por meio da Lei no 996, de 14 de julho de 1998, com uma área de 88.928,88 ha. Posteriormente, por meio da Lei no 1.319, de 04 de abril de 2002, teve sua área aumentada para 90.017,89 ha. Está localizado na região centro-oeste do Estado do Tocantins, ao norte da Ilha do Bananal, a 250 quilômetros de Palmas, capital do Estado. Toda a sua extensão abrange o município de Pium, entretanto sua sede administrativa localiza-se no município de Caseara, tendo seu Plano de Manejo elaborado no período de 1999 a 2000 e aprovado em 25 de agosto de 2005 (SEPLAN, 2016). 
Quadro 1: Características dos Parques Estaduais do Tocantins.

\begin{tabular}{|c|l|l|l|l|l|}
\hline \multicolumn{1}{|c|}{ Unidade } & $\begin{array}{c}\text { Lei a Ano de } \\
\text { Criação }\end{array}$ & Abrangência & \multicolumn{1}{c|}{ Área (ha) } & \multicolumn{1}{c|}{ Bioma } & \multicolumn{1}{c|}{ Motivo da Criação } \\
\hline $\begin{array}{l}\text { Parque Estadual } \\
\text { do Cantão (PEC) }\end{array}$ & $\begin{array}{l}\text { Lei } n^{\circ} 996 \text { de } 14 \\
\text { de julho de } 1998\end{array}$ & $\begin{array}{l}\text { Município de } \\
\text { Pium }\end{array}$ & $\begin{array}{l}88.928,88 \\
\text { ha }\end{array}$ & $\begin{array}{l}\text { Transição } \\
\text { Cerrado/ } \\
\text { Amazônia }\end{array}$ & $\begin{array}{l}\text { Conservação da biodiversidade e } \\
\text { a singularidade das belezas } \\
\text { cênicas }\end{array}$ \\
\hline $\begin{array}{l}\text { Parque Estadual } \\
\text { do Jalapão (PEJ) }\end{array}$ & $\begin{array}{l}\text { Lei } n^{\circ} 1203 \text { de } \\
12 \text { de maio de } \\
2001\end{array}$ & $\begin{array}{l}\text { Município de } \\
\text { Mateiros }\end{array}$ & $\begin{array}{l}158.885,46 \\
\text { ha }\end{array}$ & Cerrado & $\begin{array}{l}\text { Conservação da biodiversidade e } \\
\text { a singularidade das belezas } \\
\text { cênicas }\end{array}$ \\
\hline $\begin{array}{l}\text { Parque Estadual } \\
\text { do Lajeado (PEL) }\end{array}$ & $\begin{array}{l}\text { Lei } \mathrm{n}^{\circ} 1.244 \text { de } \\
11 \text { maio de } 2001\end{array}$ & $\begin{array}{l}\text { Município de } \\
\text { Palmas }\end{array}$ & $9.930,92$ ha & Cerrado & Compensação Ambiental \\
\hline
\end{tabular}

Fonte: SEPLAN $(2003 ; 2005 ; 2016)$.

Sua criação teve motivação eminentemente conservacionista, entretanto foi implantado sem consultar a comunidade local, o que gerou muitos conflitos com agricultores sazonais que possuíam terras na porção norte do PEC, desde a década de 1970, e ainda aguardam pela regularização fundiária e pela conclusão do processo de desapropriação, desde a criação do parque, em 1998 (GONÇALVES, 2013).

Essa unidade de conservação protege 325 espécies de aves, 299 espécies de peixes, além da maior população do recém-descoberto boto do Araguaia, o Inia araguaiensis; da maior população de ariranhas, jacaré-açu, onças-pintadas, harpias, entre outros animais. Sua riqueza biológica deve-se ao fato de que o Cantão, formado como um delta pelos rios Araguaia, Javaés e do Côco, apresenta mais de 800 lagos e um ecótono entre o Cerrado e a Floresta Amazônica, possuindo aproximadamente $83 \mathrm{~km}$ de comprimento por $12 \mathrm{~km}$ de largura (SEPLAN, 2016).

Em relação ao PEJ, este foi criado pela Lei Estadual 1.203, de 12 de janeiro de 2001. Está inserido na área nuclear da região do Jalapão, representando 158.885,46 hectares, com o objetivo de conservar a biodiversidade e as belezas cênicas. Mesmo com tamanha dimensão, a área total do PEJ se concentra em apenas um município tocantinense, Mateiros, sendo que seus limites atingem os marcos divisórios deste com os municípios de Ponte Alta do Tocantins, São Felix do Tocantins e Novo Acordo. O PEJ possui importantes áreas de mananciais hídricos com grande qualidade e outras características físicas relevantes, associadas a uma biota de alto valor biológico, com várias espécies da fauna e flora ainda desconhecidas da Ciência (SEPLAN, 2003).

Apesar de ser o Parque de maior dificuldade de acesso, estando distante 305 quilômetros da capital Palmas, por estradas não-pavimentadas, recebem muitos turistas que buscam seus atrativos turísticos de cunho ecológico. Por fim, o PEL foi criado pelo governo Estadual, através da Lei n 1.244, em 11 maio de 2001 e fica a cerca de $32 \mathrm{Km}$ da Capital, pela estrada de Aparecida do Rio Negro. Está inserido no Domínio Cerrado e possui características importantes para a manutenção do equilíbrio ambiental, como água em abundância e heterogeneidade ambiental, que mantém uma rica fauna regional, tendo sido identificado em seu entorno 41 espécies de mamíferos, 219 de aves, quatro de répteis e 50 anfíbios ocorrentes (SEPLAN, 2005).

O seu processo de criação está ligado à necessidade de compensação ambiental pelos impactos decorrentes do processo de implantação da Usina Hidrelétrica Luís Eduardo Magalhães (ou UHE Lajeado). Contudo, estudos realizados por Furtado e Cristo (2018) apontaram que a área escolhida para a implantação do Parque já apresentava mais de $70 \%$ da sua cobertura vegetal natural suprimida. 


\section{Procedimento metodológico}

A pesquisa foi fundamentada na análise documental, que é uma metodologia utilizada na coleta de informação em documentos de órgãos públicos e privados de qualquer natureza, ou com pessoas (TOBAR et al., 2003). Os dados foram levantados junto à SEMARH, após o Instituto Natureza do Tocantins NATURATINS, conceder autorização para realização de pesquisas em Unidades de Conservação (APUC - 41, processo № 5917-2018, Proc.:3756-2018-B). Desta forma obteve-se acesso aos arquivos completos da Ferramenta Tracking Tool, com dados correspondentes ao período de 2009 a 2018, entretanto sem dados disponíveis para os anos de 2010 e 2011.

O Tracking Tool é composto por uma lista genérica de ameaças enfrentadas pelas áreas protegidas e a classificação dos impactos, através de um Formulário de Avaliação (Scorecard) preenchido pelo gestor da UC, contendo 33 questões apresentadas em formato de tabela em Planilha de Excel, com uma pontuação variando de 0 (ruim) a 3 (excelente), que é aplicada a quatro alternativas de respostas, com um espaço reservado para identificação das duas principais ameaças e duas atividades consideradas mais críticas para o gerenciamento da UC.

Os resultados obtidos foram interpretados de acordo com o que preconiza a ferramenta utilizada, sendo que de 0 - 19 pontos considera-se a efetividade de gestão Insatisfatória; de 20 - 38 a efetividade de gestão Precisa Melhorar; de 39 - 57 a efetividade de gestão é Regular; de 58 - 77 a efetividade de gestão é Boa e de 78 - 96 a efetividade de gestão é Ótima. As análises das planilhas possibilitaram identificar a pontuação atribuída pelos gestores em cada uma das perguntas e os comentários sobre elas, sendo possível analisar os fatores que influenciaram na gestão, as ameaças e atividades críticas ao gerenciamento dos Parques Estaduais objetos da pesquisa, que foram tabuladas e trabalhadas.

\section{RESULTADOS E DISCUSSÃO}

Após a aplicação da Ferramenta Tracking Tool, os resultados demonstraram que as notas de avaliação dos parques em questão oscilaram entre 38 e 74, considerando todos os anos e UCs analisadas. Dos três Parques, o melhor avaliado foi o PEC, sendo as maiores notas obtidas nos anos de 2014 e 2015 e as menores em 2009 e 2012. O segundo melhor avaliado foi o PEJ, com os melhores resultados nos anos de 2017 e 2018 e os piores também em 2009 e 2012. Por fim, o PEL obteve sua melhor pontuação no ano de 2013 e a menor nos anos de 2009, 2015 e 2016, sendo este o mais próximo à capital do Estado e o pior avaliado, com apenas dois conceitos considerados Bons e seis considerados Regulares nesse período (Tabela 1).

Para Ferreira et al. (2012), é essencial identificar os problemas das UCs e acompanhar a gestão dos sistemas de áreas protegidas, com o objetivo de definir estratégias e prioridades que assegurem redes representativas e funcionais dos ecossistemas naturais do Brasil. Ainda segundo esses autores, desde 1986 vem sendo desenvolvidos diversos métodos para a avaliação da efetividade de gestão das UCs, ainda que de forma esporádica e isolada. 
Tabela 1: Resultados do Tracking Tool para o PEC, PEJ e PEL entre os anos de 2009 e 2018

\begin{tabular}{|l|l|l|l|l|l|l|}
\hline \multirow{2}{*}{ Ano } & \multicolumn{2}{l|}{$\begin{array}{l}\text { Parque Estadual do Cantão } \\
\text { (PEC) }\end{array}$} & \multicolumn{2}{l|}{$\begin{array}{l}\text { Parque Estadual do Jalapão } \\
\text { (PEJ) }\end{array}$} & \multicolumn{2}{l|}{$\begin{array}{l}\text { Parque Estadual do Lajeado } \\
\text { (PEL) }\end{array}$} \\
\cline { 2 - 7 } & Nota & Conceito & Nota & Conceito & Nota & Conceito \\
\hline 2018 & 56 & Regular & 74 & Bom & 56 & Regular \\
\hline 2017 & 54 & Regular & 68 & Bom & 60 & Bom \\
\hline 2016 & 52 & Regular & 58 & Bom & 40 & Regular \\
\hline 2015 & 71 & Bom & 46 & Regular & 40 & Regular \\
\hline 2014 & 74 & Bom & 62 & Bom & 47 & Regular \\
\hline 2013 & 65 & Bom & 63 & Bom & 66 & Bom \\
\hline 2012 & 49 & Regular & 40 & Regular & 44 & Regular \\
\hline 2009 & 50 & Regular & 38 & Precisa Melhorar & 40 & Regular \\
\hline Média & $\mathbf{5 8 , 8 7}$ & Bom & $\mathbf{5 6 , 1 2}$ & Regular & $\mathbf{4 9 , 1 2}$ & Regular \\
\hline
\end{tabular}

Fonte: SEMARH (2019).

Segundo Gonçalves (2013), uma ferramenta similar ao Tracking Tool, foi utilizada no ano de 2008 para monitoramento de projetos de apoio à consolidação de UCs do grupo de Proteção Integral do Tocantins pela ONG The Nature Conservancy (TNC), a partir de um formulário de avaliação (Scorecard) contendo 16 indicadores distribuídos em cinco pontos de referência. Os resultados na época também apontaram o PEC com a melhor pontuação, dentre as UCs de Proteção Integral do Tocantins sob jurisdição estadual.

Quando analisada a quantidade de anos que as UCs mantiveram os conceitos e não as notas, identificou-se que o PEJ foi o que permaneceu com os melhores resultados, sendo que em 5 dos 8 anos avaliados, obteve o conceito Bom, mantendo-se o PEL novamente com a pior avaliação ao longo de 6 anos, com o conceito Regular (Figura 2).

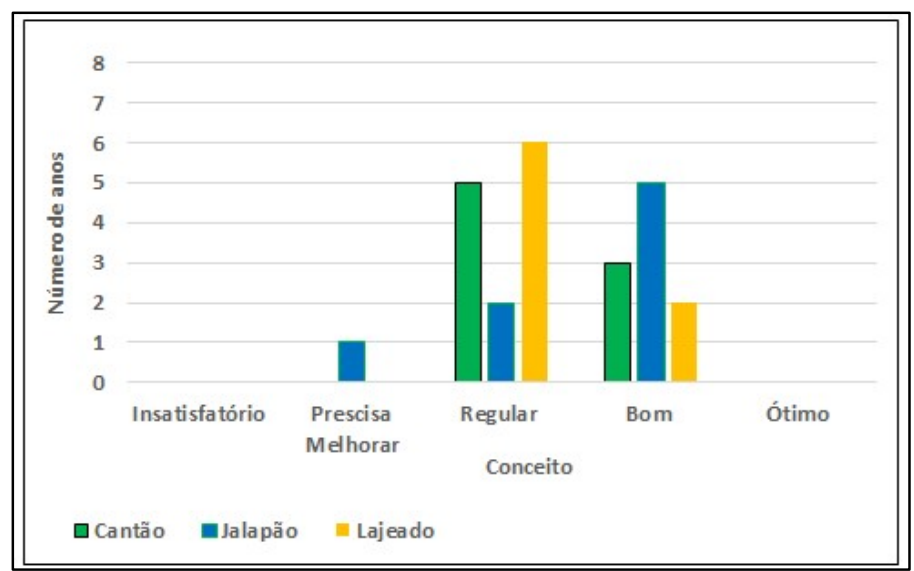

Figura 2: Frequência de conceitos obtidos pelos Parques Estaduais do Cantão (PEC), Jalapão (PEJ) e Lajeado (PEL) no período entre 2009 e 2018.

O PEC na média geral obteve o conceito Bom. Contribuíram na composição desse resultado a elevação das notas do PEC nos anos de 2014 e 2015, a proposta de revisão do Plano de Manejo como meta, utilizando recursos de compensação ambiental. Também teve fator positivo na avaliação do gestor, conforme informações no Tracking Tool de 2014, a expectativa da posse de novos servidores junto a UC, em decorrência do concurso do Estado realizado no período.

Ainda de acordo com as informações encontradas sobre o PEC, quando analisado a questão envolvendo Regulamentação da Área Protegida, verificou-se que durante os anos de 2009 e 2012 existiam mecanismos para controlar o uso inadequado do solo na UC, porém o número de funcionários do Parque era insuficiente para que esse controle fosse realizado de modo eficaz, afetando negativamente a avaliação da 
unidade. Por meio dos registros nas avaliações de 2014, 2015 e 2018, identificou-se que o problema permaneceu, apontando que a questão fundiária estava prejudicando o desenvolvimento da UC e que o quadro de servidores era insuficiente para a realização dos trabalhos, principalmente das ações fiscalizatórias. Outro problema identificado, em especial no ano de 2016 , foi a pequena participação das comunidades locais nas discussões relacionadas à gestão e manejo, pois elas não tiveram um envolvimento direto nas decisões finais sobre a UC.

O PEJ, na média geral das notas, enquadrou-se no conceito Regular. Mesmo assim, existiram fatores positivos que contribuíram para o aumento na avaliação por parte do gestor no período entre 2012 a 2014 . Entre eles está a implementação do Plano de Manejo da UC e o fato de terem recebido veículos e equipamento como GPS, Máquinas Fotográficas e Computadores novos, para acompanhamento das atividades, embora em quantidade insuficiente.

Contudo, merece destaque a questão envolvendo a Manutenção de Equipamentos e Instalações, que apresentou os mesmos problemas nos anos de 2012, 2013 e 2014, quando foi relatada a inexistência de uma sistematização do processo de manutenção de equipamentos. Segundo os registros no Tracking Tool, existia uma dependência da sede administrativa do NATURATINS para realização das manutenções e o orçamento disponível não atendia ao básico necessário à uma boa gestão, o que ocasionou uma grande limitação à capacidade de gestão da UC. Assim o processo burocrático existente e a morosidade dos setores cabíveis travaram o processo de aquisição de serviços de manutenção da UC, impactando na avaliação dela.

Outra situação que contribuiu para o PEJ obter o conceito Regular foi o fato de contar com poucos funcionários qualificados para as áreas administrativas e de monitoramento ambiental, existindo muitas lacunas em áreas específicas que necessitavam de capacitação, situação essa que não foi resolvida entre os anos de 2009 e 2014. Analisando o cenário geral, o PEL, que também obteve o conceito Regular, foi o pior avaliado. Isso significa que a UC precisa de atenção, pois a análise indica uma tendência de persistência dos mesmos problemas apontados pelos gestores.

Entre os fatores positivos encontrados na avaliação do PEL está a questão envolvendo o Estado e Vizinhança Comercial que contribuiu para o aumento na avaliação, onde o gestor destacou o aumento no contato entre gestores e vizinhança, havendo uma cooperação substancial na gestão da Área Protegida. Também contribuiu para o aumento na nota a questão sobre Avaliação das condições da Área Protegida, que apresentou destaque positivo quanto aos recursos naturais, que permaneceram conservados no período.

Dentre os motivos que contribuíram negativamente para as avaliações, encontra-se o Turismo, pois segundo as informações inseridas no Tracking Tool, além do Parque não apresentar as mesmas belezas cênicas, como as encontradas na região do Jalapão, existem problemas que dificultam a sua integração ao Turismo, como demonstrado no comentário de seu gestor, quando diz que 'não há na Unidade uma exploração efetiva do potencial turístico devido à falta de estrutura e de Plano de Uso Público, e ainda há pouco contato junto às operadoras que gerenciam esse segmento'. É importante ressaltar que consta no Plano de Manejo do Parque que este ofereça atrativos ambientais para a visitação, podendo ser uma fonte de recursos financeiros (SEPLAN, 2005). 
No momento o PEL permite visitação com agendamento, principalmente de grupos escolares, pois não possui estrutura adequada para receber os visitantes. Conforme registro Tracking Tool, em 2013 foi solicitada uma adequação em relação à estrutura do Parque, por meio do Projeto de Desenvolvimento Regional Integrado e Sustentável (PDRIS), entretanto o PEL não havia sido contemplado até 2018 com as solicitações pleiteadas.

Destaca-se que esses problemas são recorrentes, devendo ser corrigidos para que a UC esteja preparada para receber turistas e, consequentemente, ser mais vista e divulgada junto à população. Segundo Lopes et al. (2014), as UCs apresentam alta riqueza natural, o que faz dessas áreas potenciais para a prática do turismo e do ecoturismo.

Apesar de nenhuma unidade ter recebido o conceito Insatisfatório, e nem o conceito Ótimo nas avaliações realizadas por seus gestores entre os anos de 2009 e 2018, observa-se avanços e retrocessos na gestão das UCs, como no caso do PEJ, que apresentou o maior crescimento nas avaliações, saindo da pior entre todas as UCs no ano de 2009 para a melhor no ano de 2018.

\section{Ameaças às Unidades de Conservação}

Através das informações inseridas no Tracking Tool, foi possível identificar as duas principais ameaças nas UCs estudadas para cada um dos anos pesquisados (Quadro 2). Salienta-se que essas informações são pertinentes às situações vivenciadas pelos diversos gestores nesse período. As ameaças se repetem e sua persistência indica que, mesmo diagnosticadas, não foram resolvidas ao longo do período pesquisado.

Quadro 2: Principais ameaças junto ao PEC, PEJ e PEL identificadas entre o período de 2009 - 2018

\begin{tabular}{|c|c|c|c|c|}
\hline Ano(s) & $\begin{array}{l}\text { Ameaças as } \\
\text { UCs }\end{array}$ & $\begin{array}{l}\text { Parque Estadual do Cantão } \\
\text { (PEC) }\end{array}$ & Parque Estadual do Jalapão (PEJ) & $\begin{array}{l}\text { Parque Estadual do } \\
\text { Lajeado (PEL) }\end{array}$ \\
\hline \multirow[b]{2}{*}{2009} & Ameaça 1 & Pesca e caça predatória & Visitação desordenada & Queimadas \\
\hline & Ameaça 2 & $\begin{array}{l}\text { Pressão do entorno e posseiros no interior do } \\
\text { Parque }\end{array}$ & Queimadas & Caça \\
\hline \multirow{2}{*}{2012} & Ameaça 1 & Pesca e caça predatória & Visitação desordenada & Queimadas \\
\hline & Ameaça 2 & $\begin{array}{l}\text { Pressão do entorno e posseiros no interior do } \\
\text { Parque }\end{array}$ & Incêndios Florestais & Caça \\
\hline \multirow{2}{*}{2013} & Ameaça 1 & Não informada & Visitação desordenada & Queimadas \\
\hline & Ameaça 2 & Não informada & Não informada & Caça \\
\hline \multirow{2}{*}{2014} & Ameaça 1 & Pesca e caça predatória & $\begin{array}{l}\text { Falta regularização fundiária e } \\
\text { incêndios florestais }\end{array}$ & Queimadas \\
\hline & Ameaça 2 & $\begin{array}{l}\text { Pressão do entorno e posseiros no interior do } \\
\text { Parque }\end{array}$ & $\begin{array}{l}\text { Turismo desordenado e manejo } \\
\text { inadequado do Capim Dourado }\end{array}$ & Caça \\
\hline \multirow[b]{2}{*}{2015} & Ameaça 1 & Pesca e caça predatória & Incêndios florestais & Queimadas \\
\hline & Ameaça 2 & $\begin{array}{l}\text { Pressão por parte do Entorno (Assentamentos) e a } \\
\text { presença dos torrãozeiros }{ }^{1} \text { no interior da UC }\end{array}$ & Falta de regularização fundiária & Caça \\
\hline \multirow[b]{2}{*}{2016} & Ameaça 1 & Pesca e caça predatória & Não informada & Queimadas \\
\hline & Ameaça 2 & $\begin{array}{l}\text { Pressão por parte do Entorno (Assentamentos) e a } \\
\text { presença dos torrãozeiros no interior da UC }\end{array}$ & Não informada & Caça \\
\hline \multirow{2}{*}{2017} & Ameaça 1 & Caça e pesca predatória & Não informada & Queimadas \\
\hline & Ameaça 2 & Queimadas criminosas & Não informada & Caça \\
\hline \multirow{2}{*}{2018} & Ameaça 1 & Caça e pesca predatória & Não informada & Queimadas \\
\hline & Ameaça 2 & Queimadas criminosas & Não informada & Caça \\
\hline
\end{tabular}

Fonte: SEMARH (2019). ${ }^{1}$ Os "torrãozeiros" são agricultores sazonais e ficaram conhecidos localmente por este nome por fazerem plantios de subsistência nos torrões, que
são as cotas mais altas do relevo da planície aluvial nos limites do PEC e que não ficam submersas durantes as cheias (GONÇALVES, 2013). 
No caso do PEC, as ameaças recorrentes estiveram concentradas na caça e na pesca, representando estas $87,5 \%$ da frequência dos relatos na ameaça 1 , seguido pela pressão, quanto à ocupação da terra, daqueles que residem no entorno e dentro da unidade, com 62,5\% para a ameaça 2 e por fim as queimadas criminosas, representando $25 \%$ dos relatos também para a ameaça 2 , sendo esta uma nova ameaça surgida nos períodos de 2017 e 2018. O avanço do agronegócio no entorno do Parque nos últimos anos, associado à ocorrência de períodos de escassez de chuvas, estão entre os principais fatores que contribuíram para este cenário.

De acordo com dados da Secretaria de Planejamento e Meio Ambiente do Estado do Tocantins SEPLAN (2016), nos últimos anos as lavouras mecanizadas, produtoras e exportadoras de soja, avançaram sobre a produção de bovinos no entorno do Parque, esta última tradicionalmente praticada na zona de influência direta do PEC. A exemplo disso, acontece a expansão da área de soja plantada no munícipio de Caseara, onde localiza-se a sede administrativa do Parque, que passou de 600 ha (38,83\%) em 2010 para 46.073 ha (73\%) do total geral da área plantada destinada a colheitas no munícipio em 2016 (IBGE, 2017).

Segundo Silva et al. (2020), foram firmados termos de acordo entre a gestão do PEC e os residentes no interior da unidade, com vistas a minimizar possíveis impactos negativos na conservação da biodiversidade, advindos das práticas produtivas realizadas por essa população, entretanto esses residentes, aguardam a resolução da questão fundiária de suas áreas desde 1998, ano em que o Parque foi criado.

Já no caso do PEJ, as ameaças recorrentes estiveram concentradas na visitação desordenada, representando estas $37,5 \%$ da frequência dos relatos na ameaça 1 , seguido pela falta de regularização fundiária e incêndios florestais, representando 25\% das respostas. Nos anos de 2016, 2017 e 2018, não houve a inserção de informações, representando $37,5 \%$ de dados ausentes para o período. Na ameaça 2, incêndios e queimadas representaram $25 \%$ das respostas, seguidos pelo Turismo desordenado e manejo inadequado do Capim Dourado com 12,5\% e a falta de regularização fundiária representando $12,5 \%$ das respostas. Nos anos 2013, 2016, 2017 e 2018 não houve registros de informações, totalizando 50\% das respostas para a ameaça, indicando possíveis dificuldades na gestão e no acompanhamento dos setores responsáveis pelo monitoramento do PEJ, em saber o porquê da ausência dessas informações.

Outros estudos realizados no PEJ revelaram existir 14 ameaças que afetam os atributos ecológicos da UC, sendo que as quatro mais críticas são: a caça, o fogo, a agricultura mecanizada no entorno e a falta de conhecimento científico (GONÇALVES, 2013). No Brasil, grande parte das UCs tem pendência em relação à situação fundiária, não resolvidas por diversos motivos. Entretanto a ausência dessa regularização é consequência direta da falta de recursos destinados à implementação e gestão das áreas protegidas. Segundo Dias (2018), a insuficiência de repasse de recursos é um problema crônico que se agravou nas últimas décadas, com a aprovação de novas áreas para compor o Sistema Nacional de Unidades de Conservação da Natureza (SNUC), que não foi acompanhada do repasse correspondente para a garantia da manutenção dessas áreas.

Por fim, no caso do PEL, $100 \%$ das respostas para as ameaças 1 e 2 estiveram relacionadas às queimadas e à caça, respectivamente. Segundo Leite (2017), alguns chacareiros fazem a limpeza da área no 
entorno da unidade por meio do uso do fogo no período de estiagem. Em muitas situações, este tende a sair do controle, provocando incêndios florestais que atingem o PEL. Quanto à caça, Gonçalves (2013) identificou que entre as espécies mais ameaçadas na unidade estão a do veado, paca, tatu e cateto.

Salienta-se, ainda, que a proximidade da unidade, localizada a pouco mais de $30 \mathrm{Km}$ da área urbana de Palmas, é um fator preponderante para aumentar a pressão sobre seu entorno, tornando-se outra ameaça juntamente com a expansão da agricultura em larga escala na porção leste e sudeste da unidade e, a expansão dos condomínios de chácaras na porção oeste e sudoeste da área da pesquisa (LEITE, 2017).

As UCs pesquisadas possuem características geográficas particulares e, ao longo do período estudado, apresentaram problemas semelhantes quanto às ameaças recorrentes. Destaca-se o número reduzido de servidores das UCS, sejam estes temporários ou permanentes, que prejudicam a gestão e, às vezes, agravada pela qualificação insuficiente para exercer o cargo ao qual foram destinados. Segundo Dias (2018), diversas UCs no Brasil também enfrentam problemas como a falta de Plano de Manejo; crônica insuficiência de pessoal responsável pelas atividades afins; conflitos com populações residentes dentro da unidade ou no seu entorno e falta de regularização fundiária das áreas protegidas, entre outras.

\section{Atividades críticas no gerenciamento das Unidades de Conservação}

Quanto às atividades críticas de gerenciamento do PEC, PEJ e PEL, também houve uma frequência de 100\% para respostas semelhantes nas atividades 1 e 2. O teor das informações esteve concentrado nas seguintes abordagens: quantidade insuficiente de guarda-parques para monitorar as UCs, prevenir e combater as queimadas anuais no interior do Parque; período de contrato temporário insuficiente para atender as demandas das UCs e o baixo quantitativo de servidores em diversas áreas, sejam efetivos ou temporários, para um bom desenvolvimento das ações dentro dessas áreas. A quantidade de servidores oscilou constantemente no período de 2009 até 2018, sendo que em 2018 as UCs do Tocantins totalizavam 45 funcionários (Figura 3).

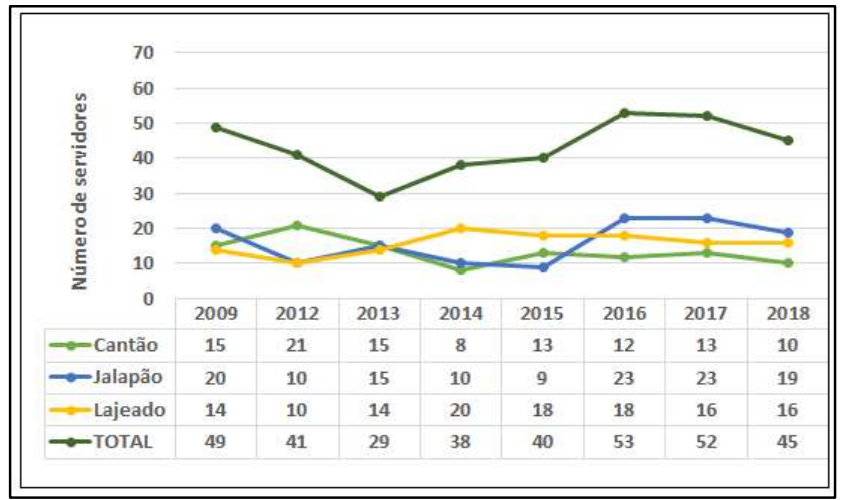

Figura 3: Evolução no quadro de servidores das UCs pesquisadas.

Ressalta-se que a alta rotatividade de servidores entre os concursados e a oscilação no número de contratos realizados em cada ano estão entre os motivos que contribuem para a constante alteração no número de servidores, impactando diretamente o planejamento das ações a médio e longo prazo. Estudos realizados por Godoy et al. (2015) relatam que o número reduzido de servidores está diretamente ligado à 
escassez de recursos, o que ocasiona uma média de um servidor para cada 18.600 hectares nas UCs Federais.

Dentre os Parques Estaduais estudados, o PEJ é o que apresenta a maior relação de área a ser monitorada por servidor. Ainda assim é mais bem avaliado quando comparado ao PEL, que possui uma área correspondente a 6,25\% do total do Parque do Jalapão, evidenciando uma discrepância entre o número de servidores, área a ser administrada e os resultados das avaliações obtidas por essas duas UCs (Tabela 2).

Tabela 2: Relação servidor e área a ser monitorada/fiscalizada

\begin{tabular}{|l|l|l|l|}
\hline Unidades de Conservação & Área & Média de Servidores entre 2009 e 2018 & Relação servidores/área \\
\hline Parque Estadual do Cantão & $88.928,88$ ha & 13 & 1 para cada $6.651,37$ ha \\
\hline Parque Estadual do Jalapão & $158.885,46$ ha & 16 & 1 para cada 9.856,41 ha \\
\hline Parque Estadual do Lajeado & $9.930,92$ ha & 15 & 1 para cada 630,53 ha \\
\hline Resultado das 3 UCs & $257.745,26$ ha & 45 & 1 para cada 5.697,28 ha \\
\hline
\end{tabular}

Em relação à esfera Federal, o Instituto Chico Mendes de Conservação da Biodiversidade (ICMBio), que é uma autarquia do Ministério do Meio Ambiente (MMA), responsável pela gestão de 334 unidades de conservação e 14 centros de pesquisa, em 2019 tinha sob sua responsabilidade uma área de 173 milhões de hectares, o equivalente a 9,1\% do território continental e $24,4 \%$ do território marinho do país, possuindo apenas 1.593 servidores, o equivalente a um para cada 100 mil hectares de área protegida. Em comparação, nos Estados Unidos, o efetivo destacado para esta atividade é 50 vezes maior (ICMBIO, 2019).

Quanto à estrutura administrativa, o PEJ e PEL apresentam estruturas semelhantes como a descrita no Plano de Manejo do PEC de 2016. Neste, o manejo é realizado por meio de Pastas (ou Coordenações) relacionadas com cada Programa do Plano de Manejo. No caso, a equipe do PEC é composta por um Supervisor de Unidades de Conservação (Gestor), um inspetor, um administrador, um assistente administrativo, um assistente de serviços gerais, três operadores de navegação fluvial, esse especifico para essa UC e cinco guarda-parques. Esses servidores podem ser efetivos, cedidos por outras áreas do governo ou contratados como no caso dos brigadistas que atuam no período da seca (SEPLAN, 2016).

Estudos realizados por Silva et al. (2020) também identificaram a situação de escassez de profissionais na equipe técnica da unidade do PEC e também foi verificado o baixo grau de investimento nas UCs, advindo de fontes estatais. Essa realidade financeira no Tocantins acabou por influenciar, significativamente, os resultados do Tracking Tool aplicado no ano de 2016, no PEC e demais UCs do Estado.

Em se tratando de atribuições, o NATURATINS é o órgão responsável pela gestão de todas as áreas de conservação na esfera estadual e em 2005, após ser criado o Sistema Estadual de Unidades de Conservação da Natureza - SEUC, ficou definido em seu Art. 60, que caberá ao NATURATINS manter um sistema de informações sobre áreas naturais protegidas do Tocantins, com a colaboração dos órgãos federais, estaduais e municipais (TOCANTINS, 2005).

Desde 2009 a Ferramenta Tracking Tool era utilizada como instrumento oficial de avaliação em projetos desenvolvidos no Tocantins com financiamento do Banco Mundial, como exemplo o Projeto de Desenvolvimento Regional Sustentável e o Projeto Cerrado Sustentável como forma de controle e monitoramento das UCs de Proteção Integral (GONÇALVES, 2013). Foi incorporada pela SEMARH para manutenção referente à gestão das UCs a partir de 2013, possibilitando a comparação da gestão das UCs ao 
longo do tempo.

Em sequência, a SEMARH desenvolveu o Sistema Informatizado de Gestão das Unidades de Conservação do Tocantins - GESTO, sendo um instrumento para o acompanhamento de gestores e comunidade quanto às UCs, que segue o fluxo de acompanhamento do processo, envolvendo a gestão dessas áreas e a divulgação de seus resultados de avaliação (Figura 4).

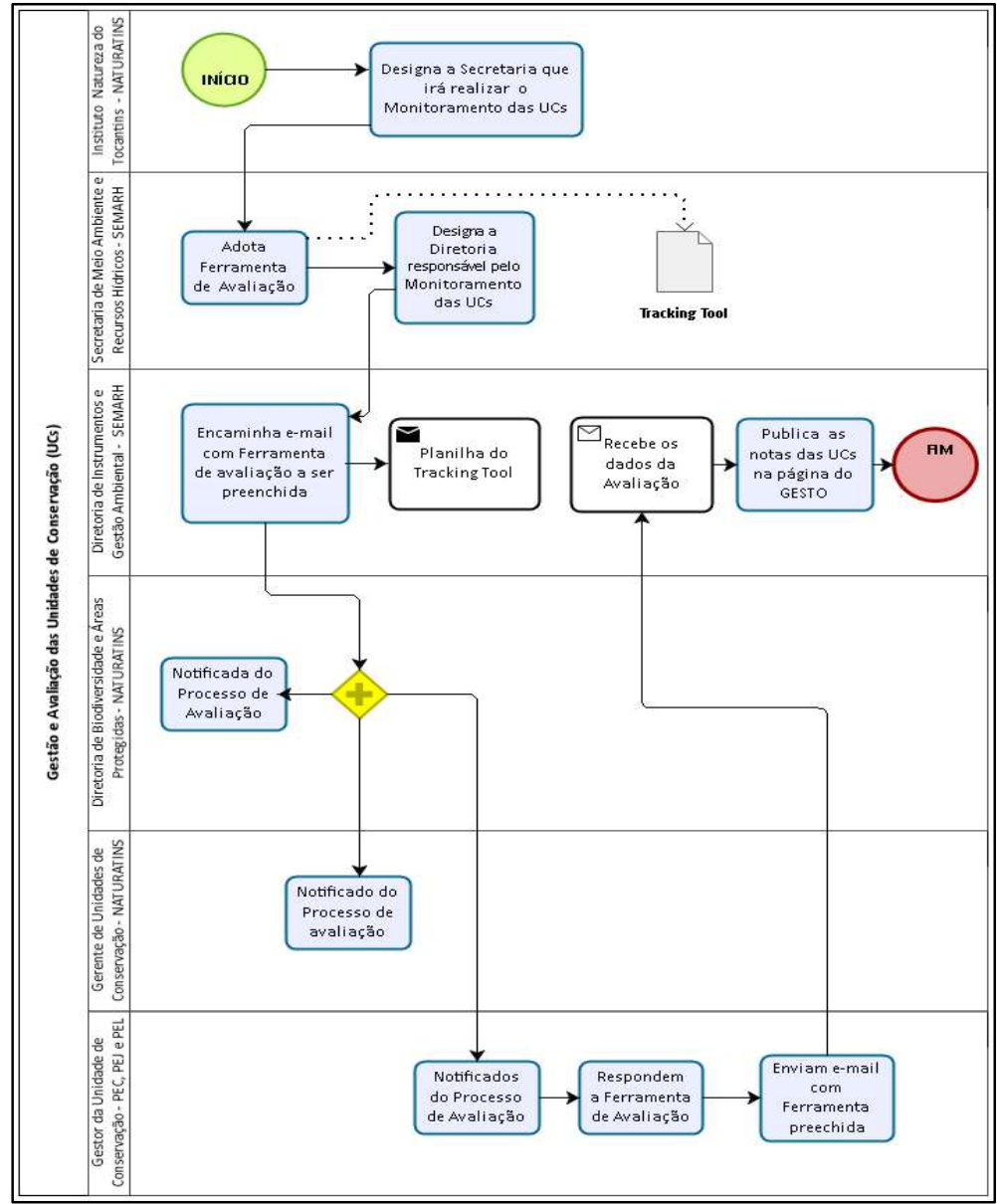

Figura 4: Processo de gerenciamento e avaliação do PEC, PEJ e PEL.

Após a análise das informações inseridas na Ferramenta Tracking Tool, foi possível mapear os pontos fortes e o que é preciso avançar em cada uma das unidades e juntamente com o mapeamento do processo de gerenciamento (Figura 4), poderão contribuir na gestão das UCs, desde que haja uma boa utilização dos resultados obtidos, sendo estes uma possibilidade para avançar na gestão dos elementos identificados como problemáticos. Contudo, para melhorar a gestão das UCs é importante considerar as singularidades de cada território e suas características socioambientais, pensando que a participação e o envolvimento das comunidades locais são elementos importantes para a conservação.

\section{CONCLUSÕES}

Em relação aos Parques Estaduais do Tocantins, verificou-se através da análise das informações obtidas via Ferramenta Tracking Tool, que são várias as situações que prejudicam uma boa avaliação por parte de seus gestores. No período de 2009 até 2018, ameaças como caça, pesca, visitação desordenada, falta de regularização fundiária, incêndios florestais e atividades críticas, como o número reduzido de 
servidores, fizeram-se presentes no cotidiano das UCs, afetando sua avaliação e o desenvolvimento das funções, contribuindo para que nenhuma dessas áreas alcançassem o conceito Ótimo. Soma-se a isso o processo burocrático existente e a morosidade dos setores cabíveis que travaram o processo de aquisição de serviços de manutenção das UCs, impactando na avaliação delas.

Todavia torna-se necessário que os órgãos responsáveis pela administração pública do PEC, PEJ e PEL realizem uma profunda análise dos resultados obtidos através do Tracking Tool, apropriem-se deles e propiciem aos gestores das UCs condições para que essas áreas cumpram o papel para as quais foram criadas, atendendo ao que preconiza a Lei no 9.985 de julho de 2000. Por fim, as informações registradas no Tracking Tool indicam quais são as principais ameaças e atividades críticas que influenciam a gestão destas UCs e podem ser fontes de pesquisas futuras com maior grau de detalhamento, contribuindo na difusão do conhecimento e avanços na gestão dessas áreas.

\section{REFERÊNCIAS}

AMBRÓSIO, R. V.. Situação Fundiária dos Parques Estaduais de Minas Gerais. Dissertação (Mestrado em Ciências Florestais) - Universidade Federal de Lavras, Lavras, 2014.

BRASIL. Lei Federal n.9985 de 18 de julho de 2000. Regulamenta o art. 225, §1으, incisos I, II, III e VII da Constituição Federal, institui o Sistema Nacional de Unidades de Conservação da Natureza e dá outras providências. Brasília: DOU, 2000

DIAS, E. S.. Conflitos no processo de constituição e regularização do Parque Nacional do Iguaçu/PR. Geografia, Londrina, v.27, n.1, p.83-102, 2018. DOI: http://dx.doi.org/10.5433/2447-1747.2018v27n1p83

DIEGUES, A. C.. O Mito Moderno da Natureza Intocada. 3 ed. São Paulo: Hucitec, 2001.

FERREIRA, I. V.. Uma política nacional para as áreas protegidas brasileiras. In: CONGRESSO BRASILEIRO DE UNIDADES DE CONSERVAÇÃO, 4. Anais. Curitiba: Fundação O Boticário de Proteção à Natureza e Rede Pró Unidades de Conservação, 2004.

FERREIRA, M. N.; KINOUCHI, M. R.; HANGAE, L. L. M.. Análise da Efetividade de Gestão das Unidades de Conservação apoiadas pelo Programa Áreas Protegidas da Amazônia (ARPA). In: Congresso Brasileiro de Unidades de Conservação, 7. Anais. Natal: Fundação O Boticário de Proteção à Natureza e Rede Pró Unidades de Conservação, 2012.

FURTADO, S. E.; CRISTO, S. S. V.. Análise das transformações ambientais no entorno do Parque Estadual do Lajeado, Palmas - Tocantins. Geografia Ensino \& Pesquisa, Santa Maria, v.22, p.1-11, 2018. DOI: http://dx.doi.org/10.5902/2236499429699

GODOY, L. R. D. C.; LEUZINGER, M. D.. O financiamento do Sistema Nacional de Unidades de Conservação no Brasil: Características e tendências. Revista de Informação Legislativa, Brasília, v.256, p.223-243, 2015.
GONÇALVES, A. B. C.. Indicadores de sustentabilidade como instrumento de análise e monitoramento da implementação do Parque Estadual do Cantão, Tocantins. Dissertação (Mestrado em Ciências do Ambiente) Universidade Federal do Tocantins, Palmas, 2013.

HIGGINS-ZOGIB, L.; MACKINNON, K.; WWF. Alliance tracking Toll: reporting conservation progress at area sites. In: HOCKINGS, M.; STOLTON, S.; LEVERINGTON, F.; DUDLEY, N.. Evaluating effectiveness: a framework for a assessing the management effectiveness of protected areas. 2 ed. Cambridge: UICN, 2006.

IBGE. Instituto Brasileiro de Geografia e Estatística. Produção Agrícola: Lavoura Temporária. Rio de Janeiro: IBGE, 2017.

HOCKINGS, M.; STOLTON, S.; LEVERINGTON, F.; DUDLEY, N.; COURRAU, J.. Evaluating effectiveness: a framework for assessing management effectiveness of protected areas. 2 ed. Cambridge: UICN, 2006.

ICMBIO. Instituto Chico Mendes de Conservação da Biodiversidade. Painel Dinâmico de Informações. Brasília: ICMBIO, 2019.

LEITE, S. E. F.. Transformações espaciais e conflitos de uso no entorno do Parque Estadual do Lajeado, Palmas Tocantins. Dissertação (Mestrado em Geografia) Universidade Federal do Tocantins, Porto Nacional, 2017.

LOPES, E. R. N.; SANTOS, A. M.. Turismo e recursos naturais: o lugar das unidades de conservação no ecoturismo. Nature and Conservation, Aquidabã, v.7, n.1, p.48-60, 2014. DOI: http://dx.doi.org/10.6008/SPC2318-2881.2014.001.0004

MEDEIROS, R.. Evolução das tipologias e categorias de áreas protegidas no Brasil. Ambiente \& Sociedade, São Paulo, v.9, n.1, p.41-64, 2006.

MORSELLO, C.. Áreas protegidas públicas e privadas: seleção e manejo. São Paulo: Fapesp, 2001. 
SANTOS, E. F.. O Processo de Criação da Reserva Biológica do Tinguá: conflitos na constituição de uma Unidade de Conservação, Nova Iguaçu-RJ (1987-1989). Dissertação (Mestrado em História Social) - Universidade do Estado do Rio de Janeiro, Rio de Janeiro, 2014.

SEMARH. Secretaria de Estado de Meio Ambiente e Recursos Hídricos do Tocantins. Relatório do Curso de Formação Básica em Gestão de Unidades de Conservação para Gestores e Guarda-parques. Palmas, 2014.

SEMARH. Secretaria de Estado de Meio Ambiente e Recursos Hídricos do Tocantins. Palmas, 2019.

MEDEIROS, R.; YOUNG, C. E. F.. Contribuição das unidades de conservação brasileiras para a economia nacional: Relatório Final. Brasília: UNEP WCMC, 2011.

TOBAR, F.; YALOUR, M. R.. Como Fazer Teses em Saúde Pública: conselhos e ideias para formular projetos e redigir teses e informes de pesquisa. Rio de Janeiro: Fiocruz, 2003.

TOCANTINS. Lei n. 1.560, de 05 de abril de 2005. Institui o Sistema Estadual de Unidades de Conservação da Natureza, e adota outras providências. Palmas: DOE, 2005.
SEPLAN. Secretaria de Planejamento e Meio Ambiente do Estado do Tocantins. Plano de Manejo do Parque Estadual do Cantão: Revisão. Palmas: SEPLAN, 2016.

SEPLAN. Secretaria de Planejamento e Meio Ambiente do Estado do Tocantins. Plano de Manejo do Parque Estadual do Jalapão. Palmas: SEPLAN, 2003.

SEPLAN. Secretaria de Planejamento e Meio Ambiente do Estado do Tocantins. Plano de Manejo do Parque Estadual do Lajeado. Palmas: SEPLAN, 2005.

SILVA, C. P.; FERREIRA, D. T. A. M.; DA GAMA, M. G.; DOS SANTOS, A. F.. Efetividade de Gestão do Parque Estadual do Cantão, Tocantins, Brasil. Revista Gestão \& Sustentabilidade Ambiental, Florianópolis, v.8, n.4, p.217-230, 2020.

UICN; WWF; IPÊ. União Internacional para Conservação da Natureza; World Wide Fund for Nature; Instituto de Pesquisas Ecológicas. Biodiversidade Brasileira: análise de situação e oportunidades, documento-base. Brasília: UICN, 2011.

VALE. Áreas protegidas: Série Integração: Transformação: Desenvolvimento. Rio de Janeiro: Fundo Vale, 2012.

A CBPC - Companhia Brasileira de Produção Científica (CNPJ: 11.221.422/0001-03) detém os direitos materiais desta publicação. Os direitos referem-se à publicação do trabalho em qualquer parte do mundo, incluindo os direitos às renovações, expansões e disseminações da contribuição, bem como outros direitos subsidiários. Todos os trabalhos publicados eletronicamente poderão posteriormente ser publicados em coletâneas impressas sob coordenação da Sustenere Publishing, da Companhia Brasileira de Produção Científica e seus parceiros autorizados. Os (as) autores (as) preservam os direitos autorais, mas não têm permissão para a publicação da contribuição em outro meio, impresso ou digital, em português ou em tradução. 